\title{
Seletividade de inseticidas usados na cultura da macieira a duas populações de Chrysoperla externa (Hagen, 1861) (Neuroptera: Chrysopidae)
}

\author{
Selectivity of insecticides used in apple orchards to two populations of Chrysoperla externa \\ (Hagen, 1861) (Neuroptera: Chrysopidae)
}

\author{
Antônio José Ferreira ${ }^{1}$ Geraldo Andrade Carvalho ${ }^{2}$ Marcos Botton ${ }^{3}$ Olinto Lasmar ${ }^{4}$
}

\section{RESUMO}

Neste trabalho, foi avaliado o efeito de inseticidas sobre larvas de duas populações de Chrysoperla externa (Hagen, 1861) (Neuroptera: Chrysopidae), oriundas de pomares de Bento Gonçalves e Vacaria, RS. O trabalho foi realizado em laboratório $\left(25 \pm 2^{\circ} \mathrm{C}\right.$, UR de $70 \pm 10 \%$ e fotofase de 12 horas) avaliando-se inseticidas, nas concentrações indicadas pelos fabricantes e/ou que estão em fase de pesquisa para o controle da mariposa oriental, lagarta enroladeira $e$ mosca-das-frutas na cultura da macieira. Os inseticidas $e$ dosagens ( $g$ ou $\mathrm{mL}$ do p.c./100L de água) avaliados foram: fosmet (Imidan 500 PM - 200), metoxifenozide (Intrepid 240 SC - 60), tebufenozide (Mimic 240 SC - 60), benzoato de emamectina (Proclaim 5 SG - 15), spinosad (Tracer 480 SC 20), etofenprox (Trebon 100 SC - 150), clorpirifós etil (Lorsban $480 \mathrm{BR}-150)$ e testemunha (somente água). As pulverizações foram realizadas em larvas de primeiro ínstar utilizando torre de Potter. Avaliaram-se a sobrevivência e a duração das fases de larva e pupa e, a fecundidade e a fertilidade dos adultos sobreviventes. A toxicidade dos produtos foi calculada em função do efeito total (E) de cada produto, conforme recomendações da IOBC. Para larvas de primeiro ínstar do crisopídeo oriundas de Bento Gonçalves, benzoato de emamectina, foi classificado como inofensivo (classe 1); metoxifenozide, etofenprox, tebufenozide, spinosad e fosmet, como levemente nocivos (classe 2) e clorpirifós, como nocivo (classe 4). Já para a população larval de C. externa de Vacaria, benzoato de emamectina, metoxifenozide, etofenprox, tebufenozide e spinosad foram inofensivos; fosmet mostrou-se moderadamente nocivo (classe 3) e clorpirifós foi nocivo.

Palavras-chave: agrotóxicos, crisopídeo, efeitos tóxicos, manejo integrado de pragas, controle biológico.

\section{ABSTRACT}

The effect of some insecticides on larvae of two populations of Chrysoperla externa (Hagen, 1861)
(Neuroptera: Chrysopidae) from Bento Gonçalves and Vacaria, $R S$ were evaluated under laboratory conditions $\left(25 \pm 2^{\circ} \mathrm{C}, \mathrm{RH}\right.$ of $70 \pm 10 \%$ and 12 hours-photophase). The compounds were used at commercial or research concentrations used to control oriental fruit moth, leaf roller and fruit fly on apple orchards. The products and rates ( $\mathrm{g}$ ou $\mathrm{mL}$ of formulated product/100L of water) evaluated were: phosmet (Imidan 500 PM - 200), methoxyfenozide (Intrepid 240 SC - 60), tebufenozide (Mimic 240 SC - 60), emamectin benzoate (Proclain 5 SG - 15), spinosad (Tracer 480 SC - 20), etofenprox (Trebon 100 SC 150) and chlorpyrifos (Lorsban 480 BR - 150), using water as control. Spraying of insecticides was on first-instar larvae using the Potter tower. The survival rate and duration, larval and pupal development time and, fecundity and fertility of survivor adults were evaluated. The toxic effect of each product was estimated by the total effect (E) according to the IOBC recommendations. Emamectin benzoate was classified as harmless (class 1) to first-instar larvae of C. externa from Bento Gonçalves. Methoxyfenozide, etofenprox, tebufenozide, spinosad and phosmet were classified as slightly harmful (class 2), and chlorpyrifos was classified as harmful (class 4). Emamectin benzoate was harmless; fosmet was moderately harmful (class 3), and chlorpyrifos was harmful to the C. externa from Vacaria.

Key words: pesticides, green lacewing, toxic effects, integrated pest management, biological control.

\section{INTRODUÇÃO}

O controle de pragas na cultura da macieira (Malus domestica (Burkh.)), tais como, a mosca-dasfrutas Anastrepha fraterculus (Wiedemann, 1830) (Diptera: Tephritidae), a mariposa oriental Grafolita molesta (Busck, 1916) (Lepidoptera: Tortricidae), a

\footnotetext{
${ }^{1}$ Departamento de Entomologia da Universidade Federal de Lavras (UFLA), CP 3037, 37200-000, Lavras, Minas Gerais, Brasil. E-mail: ajferr@ufla.br. Autor para correspondência.

${ }^{2}$ Departamento de Entomologia, UFLA, Lavras, MG, Brasil.

${ }^{3}$ Pesquisador Embrapa Uva e Vinho, Bento Gonçalves, RS, Brasil.

${ }^{4}$ Curso de Agronomia, UFLA, Lavras, MG, Brasil.
} 
lagarta-enroladeira Bonagota cranaodes (Meiryck, 1937) (Lepidoptera: Tortricidae), o ácaro-vermelhoeuropeu Panonychus ulmi (Koch, 1836) (Acari: Tetranychidae) e outras, tem sido realizado basicamente através do uso de inseticidas fosforados de amplo espectro de ação. Estes produtos apresentam sérias restrições de uso com destaque para a elevada toxicidade a organismos não-alvo e a possibilidade de acúmulo de resíduos nos frutos (KOVALESKI \& RIBEIRO, 2003).

O sistema de Produção Integrada de Maçã (PIM), iniciado na região sul do Brasil em 1997, acompanha uma tendência global de redução na utilização de insumos químicos na fruticultura. A adequação da cultura da macieira às normas desse sistema é uma exigência do mercado internacional, principalmente da União Européia que, desde 2003, impossibilita a importação do produto se produzido no sistema convencional. Os inseticidas com utilização permitida na PIM são selecionados pela sua qualidade de eficácia no controle das pragas-alvo, aliada a outras características específicas que os tornam menos agressivos ao agroecossistema. Dessa forma, buscamse diminuir os efeitos nocivos, tais como o aumento da suscetibilidade da cultura a pragas secundárias e a redução dos agentes de controle biológico existentes no agroecossistema (KOVALESKI \& RIBEIRO, 2003).

Entre os insetos benéficos encontrados em pomares de maçãs comerciais, encontra-se o crisopídeo Chrysoperla externa (Hagen, 1861) (Neuroptera: Chrysopidae) (RIBEIRO \& FLORES, 2002), que é um predador natural de ácaros, pulgões, cochonilhas e ovos de lepidópteros (CARVALHO \& SOUZA, 2000), tendo sido observado predando ninfas do pulgão lanígero Eriosoma lanigerum (Hausmann, 1802), ninfas do piolho-de-são-josé Quadraspidiotus perniciosus (Comstock, 1881), adultos e ninfas do pulgão verde Aphis citricola (Van der Goot, 1912) (ORTH et al., 1986; RIBEIRO \& FLORES, 2002) e ovos, ninfas e adultos do ácaro-vermelho-europeu $\boldsymbol{P}$. ulmi (LORENZATO, 1987).

Uma das estratégias de preservação de inimigos naturais é a utilização de inseticidas seletivos, tornando-se assim necessária a realização de estudos para a obtenção de produtos fitossanitários que sejam eficazes no controle das pragas e, ao mesmo tempo, causem os menores impactos possíveis sobre os agentes de controle natura. De acordo com RUMPF et al. (1997), os resultados experimentais de mortalidade de uma espécie de crisopídeo obtidos em determinado pomar, nem sempre podem ser extrapolados para prever efeitos tóxicos em outra população, presente em outro pomar que possui diferentes características.
Conseqüentemente, para se determinar a conveniência do uso de inseticidas em programas de manejo integrado, os efeitos desses compostos devem ser avaliados sobre as espécies benéficas nativas da respectiva localidade.

Assim, este trabalho teve como objetivo avaliar os efeitos de sete inseticidas, utilizados na cultura da macieira, sobre larvas de primeiro ínstar de C. externa oriundas de dois municípios do Rio Grande do Sul e reflexos nas fases subseqüentes do seu desenvolvimento até a fase adulta.

\section{MATERIAL E MÉTODOS}

\section{Criação de manutenção de $\boldsymbol{C}$. externa}

As criações foram iniciadas com crisopídeos coletados nos municípios de Bento Gonçalves em cultivos de videira e de Vacaria em pomares de macieira, no Estado do Rio Grande do Sul. Os crisopídeos foram coletados na fase de larva de segundo e/ou terceiro ínstares, tendo sido alimentados em laboratório com pulgões coletados em serralha (Sonchus sp.). Na fase de pupa, os exemplares foram enviados ao Laboratório de Estudos de Seletividade do Departamento de Entomologia da UFLA, onde cada população foi mantida individualizada, à temperatura de $25 \pm 2^{\circ} \mathrm{C}$, umidade relativa de $70 \pm 10 \%$ e fotofase de 12 horas.

Os crisopídeos foram criados em gaiolas cilíndricas de PVC de $15 \mathrm{~cm}$ de diâmetro por $20 \mathrm{~cm}$ de altura, revestidas internamente com papel-filtro branco que serviu como substrato de oviposição, seguindo metodologia utilizada por RIBEIRO et al. (1991).

\section{Bioensaios com C. externa}

Os bioensaios foram realizados no período de janeiro a julho de 2003, seguindo metodologia estabelecida pela Organização Internacional para o Controle Biológico e Integrado de Plantas e Animais Nocivos (IOBC) (HASSAN et al., 1994).

O delineamento experimental foi inteiramente casualizado, com cinco repetições contendo quatro larvas cada, em esquema fatorial 2 x 7 (populações Bento Gonçalves e Vacaria x inseticidas), além da testemunha que conteve somente água. Os inseticidas e dosagens (g ou $\mathrm{mL}$ do p.c./100 L de água) avaliados foram: fosmet (Imidan 500 PM - 200), metoxifenozide (Intrepid 240 SC - 60), tebufenozide (Mimic 240 SC 60 ), benzoato de emamectina (Proclaim 5 SG - 15), spinosad (Tracer 480 SC - 20), etofenprox (Trebon 100 SC - 150), clorpirifós etil (Lorsban $480 \mathrm{BR}$ - 150) e testemunha (somente água).

Aproximadamente 12 horas após a eclosão, vinte larvas (quatro larvas/parcela x cinco repetições) 
de primeiro ínstar da quinta geração das duas populações, obtidas da criação de manutenção, foram separadas, por tratamento e população, em placas de Petri de $15 \mathrm{~cm}$ de diâmetro e submetidas aos inseticidas, em pulverização por meio de torre de Potter. O equipamento foi ajustado a uma pressão de $15 \mathrm{lb} \cdot \mathrm{pol}^{-2}$, possibilitando a aplicação de $1,5 \pm 0,5 \mathrm{mg}$ de calda. $\mathrm{cm}^{-2}$.

Após submetidas aos tratamentos, as larvas foram individualizadas em tubos de vidro de $8,5 \mathrm{~cm}$ de altura por 2,5cm de diâmetro, evitando, assim, a ocorrência de canibalismo, tendo sido alimentadas ad libitum com ovos de Anagasta kuehniella (Zeller, 1879) (Lepidoptera: Pyralidae). Os tubos foram vedados com filme plástico de PVC laminado e levados para câmara climatizada ( $25 \pm 2^{\circ} \mathrm{C}$, UR $70 \pm 10 \%$ e fotofase de $12 \mathrm{~h}$ ). As pupas formadas foram mantidas nos tubos de vidro até a emergência dos adultos. Em todas essas fases, foram feitos os registros de duração e de sobrevivência dos insetos que foram posteriormente utilizados nas análises estatísticas.

\section{Avaliação dos efeitos sub-letais dos inseticidas sobre} C. externa

Dos adultos emergidos, separaram-se cinco casais, por tratamento, que foram mantidos em gaiolas cilíndricas de PVC de $10 \mathrm{~cm}$ de altura por $10 \mathrm{~cm}$ de diâmetro. O preparo das gaiolas e a dieta foram semelhantes àquelas utilizadas na criação de manutenção, diferindo apenas no fechamento da parte superior da gaiola, que foi com tecido tipo "voil" (CARVALHO \& SOUZA, 2000) e no fornecimento da dieta. A dieta foi aplicada sobre um pedaço de esponja porosa, ajustada na abertura de um recipiente de vidro (10 ml), contendo água destilada, que foi fixado na parte superior da gaiola. Acompanhou-se a oviposição desses casais por 30 dias consecutivos após a primeira postura. Os ovos foram contados em intervalos de três dias, quando se procedia a substituição das dietas. Em quatro dessas contagens, 96 ovos por tratamento foram individualizados em compartimentos de placas de microtitulação usadas em testes ELISA (Enzyme Linked Immunosorbent Assay), cobertas com filme plástico de PVC laminado e mantidas nas mesmas condições climáticas da criação de manutenção, para se avaliar a viabilidade dos mesmos.

Avaliaram-se a sobrevivência e a duração das fases de larva e de pupa, a fecundidade dos casais formados após a emergência dos adultos e a viabilidade dos ovos produzidos pelas fêmeas desses casais, que foram provenientes das larvas de primeiro ínstar tratadas.

Análise dos dados obtidos

A toxicidade dos inseticidas foi calculada em função do efeito total (E) de cada produto, baseando-se na mortalidade dos indivíduos ao longo do desenvolvimento e na redução de sua capacidade reprodutiva, segundo a fórmula proposta por VOGT (1992): $\mathrm{E}=100 \%-(100 \%-\mathrm{M} \%) \times \mathrm{R} 1 \times \mathrm{R} 2$, sendo $\mathrm{E}=$ efeito total (\%); $\mathrm{M} \%=$ mortalidade no tratamento corrigida pela fórmula de ABBOTT (1925); R1 = razão entre a média diária de ovos ovipositados por fêmea tratada e não tratada e R2 = razão entre a viabilidade média de ovos ovipositados por fêmea tratada e não tratada.

Após a obtenção do efeito total, cada composto foi enquadrado nas classes de toxicidade conforme HASSAN et al. (1994), sendo: classe $1=$ inofensivo $(E<30 \%)$, classe 2 = levemente nocivo $(30 \% \leq \mathrm{E} \leq 79 \%)$, classe $3=$ moderadamente nocivo $(80 \% \leq E \leq 99 \%)$ e classe $4=$ nocivo $(E>99 \%)$.

Os dados foram submetidos à análise de variância e as médias dos tratamentos foram comparadas pelo teste de Tukey a 5\% de significância, utilizando-se o programa de análises estatísticas SAS (SAS INSTITUTE, 1998).

\section{RESULTADOS E DISCUSSÃO}

Efeito dos inseticidas sobre a duração dos ínstares larvais e de pupas de $\boldsymbol{C}$. externa

Uma vez que o contato com o inseticida clorpirifós provocou a morte de $100 \%$ das larvas antes de completarem o primeiro ínstar, não foi possível avaliar os efeitos desse produto na duração das larvas e de pupas e na sobrevivência de larvas do segundo ínstar em diante (Tabelas 1 e 2).

Os inseticidas pulverizados, exceto clorpirifós, não afetaram a duração do período de pupas, larvas de primeiro, segundo e terceiro ínstares, dentro de cada população (Tabelas 1 e 2). Também não se observaram diferenças entre as duas populações de C. externa no desenvolvimento da fase larval total (9,2 e 8,7 dias), larvas de primeiro (3,4 e 3,1 dias) e terceiro (3,0 e 3,1 dias) ínstares, para as populações de Bento Gonçalves e de Vacaria, respectivamente. A população de Vacaria apresentou redução de 22,2; 27,6; 14,3 e 13,8\% na duração do segundo ínstar, quando submetida aos inseticidas metoxifenozide, tebufenozide, benzoato de emamectina e etofenprox, se comparada à população de Bento Gonçalves, respectivamente (Tabela 1 ).

Na população de Vacaria, as larvas do crisopídeo submetidas à aplicação de tebufenozide e benzoato de emamectina apresentaram uma redução de 10 e 6,7\% na duração total da fase larval, quando comparada ao tratamento testemunha (Tabela 1). Isto 
Tabela 1 - Duração (dias) ( \pm EP) do primeiro, segundo e terceiro ínstares e da fase larval de Chrysoperla externa provenientes de larvas de primeiro ínstar tratadas com sete inseticidas, mais a testemunha. Temp.:25 $\pm 2^{\circ} \mathrm{C}$; UR: $70 \pm 10 \%$; fotofase: $12 \mathrm{~h}$; $\left.\mathrm{n}=20\right)^{1}$.

\begin{tabular}{|c|c|c|c|c|c|c|}
\hline \multirow{2}{*}{ Tratamentos } & \multicolumn{2}{|c|}{ Primeiro ínstar } & \multicolumn{4}{|c|}{ Segundo ínstar } \\
\hline & B. Gonçalves & Vacaria & & B. Gonçalves & Vacaria & \\
\hline Fosmet & $3,5 \pm 0,11$ & $3,2 \pm 0,09$ & $3,4 \pm 0,07 \mathrm{a}$ & $2,5 \pm 0,19 \mathrm{~A} \mathrm{a}$ & $2,8 \pm 0,16 \mathrm{~A} \mathrm{a}$ & $2,6 \pm 0,12$ \\
\hline Metoxifenozide & $3,2 \pm 0,09$ & $3,1 \pm 0,10$ & $3,1 \pm 0,06$ a & $2,7 \pm 0,15 \mathrm{~A} \mathrm{a}$ & $2,1 \pm 0,15 \mathrm{~B} \mathrm{a}$ & $2,4 \pm 0,10$ \\
\hline Tebufenozide & $3,4 \pm 0,08$ & $3,0 \pm 0,09$ & $3,2 \pm 0,08$ a & $2,9 \pm 0,16 \mathrm{~A}$ a & $2,1 \pm 0,14 \mathrm{~B} \mathrm{a}$ & $2,5 \pm 0,11$ \\
\hline $\begin{array}{l}\text { Benzoato de } \\
\text { emamectina }\end{array}$ & $3,2 \pm 0,09$ & $3,0 \pm 0,08$ & $3,1 \pm 0,06$ a & $2,8 \pm 0,15 \mathrm{~A} \mathrm{a}$ & $2,4 \pm 0,16 \mathrm{~B} \mathrm{a}$ & $2,6 \pm 0,12$ \\
\hline Spinosad & $3,5 \pm 0,10$ & $3,3 \pm 0,09$ & $3,4 \pm 0,07$ a & $2,9 \pm 0,14 \mathrm{~A} \mathrm{a}$ & $2,7 \pm 0,15 \mathrm{~A} \mathrm{a}$ & $2,8 \pm 0,10$ \\
\hline Etofenprox & $3,6 \pm 0,08$ & $3,2 \pm 0,07$ & $3,4 \pm 0,08$ a & $2,9 \pm 0,15 \mathrm{~A} \mathrm{a}$ & $2,5 \pm 0,14 \mathrm{~B} \mathrm{a}$ & $2,7 \pm 0,11$ \\
\hline Testemunha & $3,3 \pm 0,09$ & $3,1 \pm 0,09$ & $3,2 \pm 0,06$ a & $2,7 \pm 0,16 \mathrm{~A} \mathrm{a}$ & $2,8 \pm 0,15 \mathrm{~A} \mathrm{a}$ & $2,7 \pm 0,10$ \\
\hline Médias & $3,4 \pm 0,04 \mathrm{~A}$ & $3,1 \pm 0,03 \mathrm{~A}$ & & $2,8 \pm 0,06$ & $2,5 \pm 0,06$ & \\
\hline CV (\%) & & & 6,04 & & & 12,60 \\
\hline \multirow{2}{*}{ Tratamentos } & \multicolumn{2}{|c|}{ Terceiro ínstar } & & \multicolumn{2}{|c|}{ Fase larval } & \\
\hline & B. Gonçalves & Vacaria & Médias & B. Gonçalves & Vacaria & Médias \\
\hline Fosmet & $3,0 \pm 0,17$ & $3,3 \pm 0,15$ & $3,1 \pm 0,11 \mathrm{a}$ & $9,0 \pm 0,26 \mathrm{~A} \mathrm{a}$ & $9,0 \pm 0,23 \mathrm{~A} \mathrm{a}$ & $9,0 \pm 0,18$ \\
\hline Metoxifenozide & $3,1 \pm 0,13$ & $3,3 \pm 0,13$ & $3,2 \pm 0,09$ a & $9,0 \pm 0,21 \mathrm{~A} \mathrm{a}$ & $8,5 \pm 0,21 \mathrm{~A} \mathrm{a}$ & $8,7 \pm 0,14$ \\
\hline Tebufenozide & $3,0 \pm 0,15$ & $3,0 \pm 0,14$ & $3,0 \pm 0,09$ a & $9,2 \pm 0,22 \mathrm{~A} \mathrm{a}$ & $8,1 \pm 0,22 \mathrm{~A} \mathrm{~b}$ & $8,7 \pm 0,15$ \\
\hline $\begin{array}{l}\text { Benzoato de } \\
\text { emamectina }\end{array}$ & $3,0 \pm 0,13$ & $3,0 \pm 0,13$ & $3,0 \pm 0,10 \mathrm{a}$ & $9,0 \pm 0,23 \mathrm{~A} \mathrm{a}$ & $8,4 \pm 0,21 \mathrm{~A} \mathrm{~b}$ & $8,7 \pm 0,16$ \\
\hline Spinosad & $2,8 \pm 0,14$ & $3,0 \pm 0,16$ & $2,9 \pm 0,09$ a & $9,2 \pm 0,21 \mathrm{~A} \mathrm{a}$ & $9,0 \pm 0,20 \mathrm{~A}$ a & $9,1 \pm 0,14$ \\
\hline Etofenprox & $3,4 \pm 0,16$ & $3,2 \pm 0,13$ & $3,3 \pm 0,08$ a & $9,8 \pm 0,24 \mathrm{~A} \mathrm{a}$ & $8,9 \pm 0,21 \mathrm{~A} \mathrm{a}$ & $9,4 \pm 0,17$ \\
\hline Testemunha & $2,9 \pm 0,13$ & $3,4 \pm 0,14$ & $3,0 \pm 0,09$ a & $8,9 \pm 0,21 \mathrm{~A} \mathrm{a}$ & $9,0 \pm 0,23 \mathrm{~A} \mathrm{a}$ & $9,0 \pm 0,14$ \\
\hline Médias & $3,0 \pm 0,05 \mathrm{~A}$ & $3,1 \pm 0,05 \mathrm{~A}$ & & $9,2 \pm 0,08$ & $8,7 \pm 0,08$ & \\
\hline CV (\%) & & & 9,54 & & & 5,21 \\
\hline
\end{tabular}

${ }^{1}$ Médias não seguidas pela mesma letra, maiúscula na linha e minúscula na coluna, diferem significativamente entre si, pelo teste de Tukey em nível de 5\% de significância.

pode ter ocorrido em função da redução da duração das larvas de segundo ínstar na população de Vacaria. Provavelmente, no somatório dos períodos de cada ínstar para se obter a duração total da fase larval ocorreu um efeito compensatório entre ínstares para os tratamentos à base de metoxifenozide e etofenprox, o que não ocorreu para tebufenozide e benzoato de emamectina.

Efeito dos inseticidas na sobrevivência dos ínstares larvais e de pupas de $\boldsymbol{C}$. externa

Os inseticidas pulverizados, exceto clorpirifós, não afetaram a sobrevivência de larvas de segundo e terceiro ínstares e de pupas dentro de cada população. Também não ocorreram diferenças na sobrevivência de todos os estádios larvais de $\boldsymbol{C}$. externa entre as duas populações (Tabela 2). Dessa forma, realizou-se uma análise conjunta para esse parâmetro, mediante a comparação dos dados médios das duas populações para cada ínstar em cada tratamento.
Clorpirifós foi altamente tóxico para larvas de primeiro ínstar do predador, provocando mortalidade de $100 \%$ em menos de 48 horas, seguido pelo fosmet (25\% de sobrevivência) e etofenprox (72,5\% de sobrevivência). Já as larvas nesse estádio quando submetidas aos inseticidas tebufenozide, spinosad, metoxifenozide e benzoato de emamectina apresentaram sobrevivência semelhante à testemunha (Tabela 2). Essas diferenças observadas no primeiro ínstar refletiram na sobrevivência do total da fase larval de $\boldsymbol{C}$. externa. A população de Bento Gonçalves apresentou menor sobrevivência pupal que a população de Vacaria (Tabela 2). Todavia, a não observância de diferenças estatísticas entre os inseticidas, com relação à sobrevivência de pupas, indica que a menor sobrevivência constatada na população de Bento Gonçalves não foi devido aos efeitos dos produtos avaliados, podendo ser atribuída a fatores aleatórios. Semelhantemente aos resultados obtidos neste trabalho, BALASUBRAMANI \& SWAMIAPPAN (1997) verificaram alta toxicidade de 
Tabela 2 - Sobrevivência (\%) ( \pm EP) de larvas de primeiro, segundo, terceiro ínstares e da fase larval, e duração (dias) ( \pm EP) e sobrevivência de pupas de Chrysoperla externa provenientes de larvas de primeiro ínstar tratadas com sete inseticidas mais a testemunha. Temp.:25 $\pm 2^{\circ} \mathrm{C}$; UR: $70 \pm 10 \%$; fotofase: $\left.12 \mathrm{~h} ; \mathrm{n}=20\right)^{1}$.

\begin{tabular}{|c|c|c|c|c|c|c|}
\hline \multirow{3}{*}{ Tratamentos } & \multicolumn{2}{|c|}{ Primeiro ínstar } & \multicolumn{4}{|c|}{ Segundo ínstar } \\
\hline & & & Médias & & & Médias \\
\hline & B. Gonçalves & Vacaria & & B. Gonçalves & Vacaria & \\
\hline Fosmet & $25,0 \pm 7,28$ & $25,0 \pm 7,28$ & $25,0 \pm 5,15$ c & $100,0 \pm 0,00$ & $80,0 \pm 6,20$ & $90,0 \pm 4,90$ a \\
\hline Metoxifenozide & $95,0 \pm 7,20$ & $90,0 \pm 7,26$ & $92,5 \pm 5,13$ a & $100,0 \pm 0,00$ & $100,0 \pm 0,00$ & $100,0 \pm 0,00 \mathrm{a}$ \\
\hline Tebufenozide & $80,0 \pm 7,25$ & $85,0 \pm 7,28$ & $82,5 \pm 5,15$ a & $100,0 \pm 0,00$ & $93,3 \pm 6,20$ & $96,7 \pm 4,39$ а \\
\hline $\begin{array}{ll}\text { Benzoato de } \\
\text { emamectina }\end{array}$ & $100,0 \pm 0,00$ & $95,0 \pm 7,25$ & $97,5 \pm 5,14$ a & $95,0 \pm 6,20$ & $95,0 \pm 6,30$ & $95,0 \pm 4,40$ a \\
\hline Spinosad & $90,0 \pm 7,26$ & $85,0 \pm 7,28$ & $87,5 \pm 5,15$ а & $95,0 \pm 6,30$ & $100,0 \pm 0,00$ & $97,5 \pm 4,39$ a \\
\hline Etofenprox & $65,0 \pm 7,28$ & $80,0 \pm 7,27$ & $72,5 \pm 5,16 b$ & $100,0 \pm 0,00$ & $100,0 \pm 0,00$ & $100,0 \pm 0,00 \mathrm{a}$ \\
\hline Clorpirifós & $0,0 \pm 0,00$ & $0,0 \pm 0,00$ & $0,0 \pm 0,00 \mathrm{~d}$ & - & - & - \\
\hline Testemunha & $100,0 \pm 0,00$ & $100,0 \pm 0,00$ & $100,0 \pm 0,0 a$ & $100,0 \pm 0,00$ & $100,0 \pm 0,00$ & $100,0 \pm 0,00 \mathrm{a}$ \\
\hline Médias & $69,4 \pm 2,58 \mathrm{~A}$ & $70,0 \pm 2,58 \mathrm{~A}$ & & $98,6 \pm 2,41 \mathrm{~A}$ & $95,5 \pm 2,34 \mathrm{~A}$ & \\
\hline CV (\%) & & & 23,38 & & & 14,30 \\
\hline \multirow{2}{*}{ Tratamentos } & \multicolumn{2}{|c|}{ Terceiro ínstar } & Médias & \multicolumn{2}{|c|}{ Fase larval } & Médias \\
\hline & B. Gonçalves & Vacaria & 1vicusas & B. Gonçalves & Vacaria & 19tecias \\
\hline Fosmet & $60,0 \pm 10,00$ & $80,0 \pm 9,00$ & $70,0 \pm 7,07$ a & $25,0 \pm 7,71$ & $20,0 \pm 7,72$ & $22,5 \pm 5,45$ c \\
\hline Metoxifenozide & $100,0 \pm 0,00$ & $100,0 \pm 0,00$ & $100,0 \pm 0,0$ a & $95,0 \pm 7,81$ & $90,0 \pm 7,71$ & $92,5 \pm 5,44 \mathrm{ab}$ \\
\hline Tebufenozide & $100,0 \pm 0,00$ & $100,0 \pm 0,00$ & $100,0 \pm 0,0$ a & $80,0 \pm 7,71$ & $80,0 \pm 7,73$ & $80,0 \pm 5,45 \mathrm{ab}$ \\
\hline $\begin{array}{ll}\text { Benzoato de } \\
\text { emamectina }\end{array}$ & $100,0 \pm 0,00$ & $100,0 \pm 0,00$ & $100,0 \pm 0,0$ a & $95,0 \pm 7,61$ & $95,0 \pm 7,71$ & $95,0 \pm 5,45 \mathrm{ab}$ \\
\hline Spinosad & $100,0 \pm 0,00$ & $100,0 \pm 0,00$ & $100,0 \pm 0,0 \mathrm{a}$ & $85,0 \pm 7,72$ & $85,0 \pm 7,61$ & $85,0 \pm 5,40 \mathrm{ab}$ \\
\hline Etofenprox & $80,0 \pm 10,00$ & $100,0 \pm 0,00$ & $90,0 \pm 0,00$ a & $65,0 \pm 7,71$ & $80,0 \pm 7,74$ & $72,5 \pm 5,43 \quad b$ \\
\hline Clorpirifós & - & - & - & $0,0 \pm 0,00$ & $0,0 \pm 0,00$ & $0,0 \pm 0,00 \quad \mathrm{c}$ \\
\hline Testemunha & $100,0 \pm 0,00$ & $100,0 \pm 0,00$ & $100,0 \pm 0,0 \mathrm{a}$ & $100,0 \pm 0,00$ & $100,0 \pm 0,00$ & $100,0 \pm 0,00 \mathrm{a}$ \\
\hline Médias & $91,4 \pm 3,78 \mathrm{~A}$ & $97,1 \pm 3,78 \mathrm{~A}$ & & $68,1 \pm 2,72 \mathrm{~A}$ & $68,8 \pm 2,72 \mathrm{~A}$ & \\
\hline CV (\%) & & & 23,71 & & & 25,17 \\
\hline \multirow{2}{*}{ Tratamentos } & \multicolumn{2}{|c|}{ Duração } & Módiac & \multicolumn{2}{|c|}{ Sobrevivência } & Módiac \\
\hline & B. Gonçalves & Vacaria & Ivieulds & B. Gonçalves & Vacaria & ivieulds \\
\hline Fosmet & $10,2 \pm 0,23$ Аа & $9,4 \pm 0,20 \mathrm{Ba}$ & $9,8 \pm 0,15$ & $100,0 \pm 0,00$ & $100,0 \pm 0,00$ & $100,0 \pm 0,00 \mathrm{a}$ \\
\hline Metoxifenozide & $9,7 \pm 0,18$ Аа & $9,9 \pm 0,18 \mathrm{Aa}$ & $9,8 \pm 0,13$ & $93,3 \pm 3,51$ & $100,0 \pm 0,00$ & $96,7 \pm 2,48$ a \\
\hline Tebufenozide & $9,9 \pm 0,19$ Аа & $10,2 \pm 0,17 \mathrm{Aa}$ & $10,0 \pm 0,14$ & $100,0 \pm 0,00$ & $100,0 \pm 0,00$ & $100,0 \pm 0,00 \mathrm{a}$ \\
\hline $\begin{array}{l}\text { Benzoato de } \\
\text { emamectina }\end{array}$ & $10,1 \pm 0,18$ Аа & $9,8 \pm 0,18 \mathrm{Aa}$ & $9,9 \pm 0,13$ & $95,0 \pm 3,51$ & $100,0 \pm 0,00$ & $97,5 \pm 2,48$ a \\
\hline Spinosad & $9,9 \pm 0,17$ Аа & $10,0 \pm 0,16$ Аа & $10,0 \pm 0,12$ & $86,7 \pm 3,53$ & $100,0 \pm 0,00$ & $93,3 \pm 2,45$ a \\
\hline Etofenprox & $9,4 \pm 0,20 \mathrm{Ba}$ & $10,2 \pm 0,19 \mathrm{Aa}$ & $9,8 \pm 0,13$ & $100,0 \pm 0,00$ & $100,0 \pm 0,00$ & $100,0 \pm 0,00 \mathrm{a}$ \\
\hline Testemunha & $10,0 \pm 0,18 \mathrm{Aа}$ & $10,2 \pm 0,18 \mathrm{Aa}$ & $10,1 \pm 0,15$ & $95,0 \pm 3,51$ & $100,0 \pm 0,00$ & $97,5 \pm 2,48$ a \\
\hline Médias & $9,9 \pm 0,07$ & $9,9 \pm 0,07$ & & $95,7 \pm 1,39$ В & $100,0 \pm 0,00 \mathrm{~A}$ & \\
\hline CV (\%) & & & 3,99 & & & 8,04 \\
\hline
\end{tabular}

${ }^{1}$ Médias não seguidas pela mesma letra, maiúscula na linha e minúscula na coluna, diferem significativamente entre si, pelo teste de Tukey em nível de $5 \%$ de significância

clorpirifós às larvas de primeiro ínstar de Chrysoperla carnea (Stephens, 1836). Este fato pode estar associado à maior penetração do composto no tegumento do predador. Ao atingir o sistema nervoso provoca inibição da enzima acetilcolinesterase com o acúmulo de acetilcolina nas sinapses, causando hiperexcitação nervosa e conseqüente sintomas de intoxicação no organismo, conforme é a característica dos inseticidas organofosforados (WILKINSON, 1976).
As reações das larvas de primeiro ínstar de C. externa aos organofosforados parecem ser específicas, já que diferenças de resposta entre clorpirifós e fosmet foram observadas. Esses produtos, possivelmente, inibiram diferentemente a enzima acetilcolinesterase desse predador. RUMPF et al. (1997) verificaram que larvas de terceiro ínstar de Micromus tasmaniae (Walker, 1860) que sobreviveram após 24 horas de exposição ao contato com superfícies tratadas

Ciência Rural, v.36, n.2, mar-abr, 2006. 
com os organofosforados metil-paratiom e azinfósmetil, sofreram redução de $20 \%$ e $51 \%$ na atividade da enzima acetilcolinesterase.

Metoxifenozide e tebufenozide agem como mímicos do ecdisônio, induzindo o início do processo de ecdise, sendo considerados mais específicos para insetos da ordem Lepidoptera (CARLSON et al., 2001). Talvez, por essa característica, não tenham apresentado efeito prejudicial à sobrevivência das larvas de $\boldsymbol{C}$. externa, conforme também constataram RETNAKARAN et al. (2001) em parasitóides de lagartas pertencentes às ordens Diptera e Hymenoptera.

A redução na sobrevivência do primeiro ínstar do predador quando submetido ao etofenprox pode ser explicada pelo mecanismo de ação desse produto. Etofenprox é um inseticida com ação similar aos piretróides, agindo predominantemente sobre o sistema nervoso central. A sua molécula interfere com os canais de íons $\mathrm{Na}^{+}$nas membranas nervosas, que levam a uma prolongada abertura desses canais. Isso causa um bloqueio dos sinais nervosos, que eventualmente resulta na morte de insetos e ácaros (YOSHIMOTO et al., 1989).

Seletividade dos inseticidas para larvas das duas populações de $\boldsymbol{C}$. externa

A classificação dos produtos quando pulverizados sobre larvas de primeiro ínstar de Bento Gonçalves obedeceu à seguinte ordem: benzoato de emamectina foi inofensivo (classe 1); fosmet, metoxifenozide, tebufenozide, spinosad e etofenprox levemente nocivos (classe 2) e clorpirifós foi nocivo (classe 4) (Tabela 3). Já para a população de Vacaria: benzoato de emamectina, metoxifenozide, etofenprox, tebufenozide e spinosad foram inofensivos (classe 1), fosmet moderadamente nocivo (classe 3) e clorpirifós foi nocivo (classe 4) (Tabela 3). GODOY et al. (2004) avaliaram o efeito de tebufenozide $\left(0,12\right.$ g i.a. $\left.\mathrm{L}^{-1}\right)$ quando aplicado sobre ovos desse crisopídeo e constataram que este composto mostrou-se inofensivo (classe 1) às fases subseqüentes do predador.

As larvas de primeiro ínstar da população de Bento Gonçalves foram mais sensíveis aos efeitos de alguns produtos do que as de Vacaria. Metoxifenozide, etofenprox, tebufenozide e spinosad foram incluídos na classe 2 para os insetos oriundos de Bento Gonçalves, para os crisopídeos da população proveniente de Vacaria foram inofensivos. A tolerância da população de $\boldsymbol{C}$. externa de Vacaria, coletada em pomares de macieira com maior exposição prévia à aplicação de inseticidas, pode ser resultado da pressão seletiva exercida nessa população, ao contrário dos crisopídeos coletados no município de Bento
Gonçalves, em áreas de videiras não submetidas à aplicação de inseticidas. De acordo com BLEICHER (1985), a procedência da linhagem ou população e a variação intraespecífica entre espécimens coletados em diferentes regiões podem ser responsáveis por alterações nos parâmetros biológicos de populações de insetos, podendo explicar divergências em suscetibilidade a inseticidas.

De modo geral, verificou-se menor impacto negativo dos produtos mais modernos (metoxifenozide, etofenprox, tebufenozide e spinosad) em comparação com aqueles pertencentes ao grupo químico dos organofosforados (clorpirifós e fosmet). Este fato demonstra a necessidade da realização de pesquisas para avaliação do efeito dos produtos pertencentes a novos grupos químicos aos principais inimigos naturais das pragas da macieira.

Recomenda-se avaliar os efeitos dos compostos que se mostraram tóxicos em laboratório, também em casa de vegetação e campo para confirmação de sua toxicidade e possível utilização em programas de manejo integrado de pragas da macieira. Nessas condições, os inimigos naturais podem ficar menos expostos aos resíduos dos produtos, em função da utilização de refúgios presentes na planta e/ou no próprio agroecossistema que podem servir como meios de escape. Além disso, em condições naturais, fatores abióticos como temperatura, luz e umidade podem contribuir para a degradação dos inseticidas, reduzindo os seus efeitos sobre os insetos.

\section{CONCLUSÃO}

Benzoato de emamectina é inofensivo (classe 1); metoxifenozide, etofenprox, tebufenozide, spinosad e fosmet são levemente nocivos (classe 2) e clorpirifós é nocivo (classe 4) para larvas de primeiro ínstar de $\boldsymbol{C}$. externa oriundas do município de Bento Gonçalves, RS. Para as larvas de primeiro ínstar de $\boldsymbol{C}$. externa provenientes de Vacaria, benzoato de emamectina, metoxifenozide, etofenprox, tebufenozide e spinosad são inofensivos; fosmet é moderadamente nocivo e clorpirifós é nocivo. A população de larvas de primeiro ínstar de Bento Gonçalves é mais sensível aos produtos que a de Vacaria. Em função da não toxicidade apresentada por benzoato de emamectina, baixa toxicidade de metoxifenozide, etofenprox, tebufenozide e spinosad, e moderada toxicidade de fosmet aos insetos das duas populações de $\boldsymbol{C}$. externa, esses compostos podem ser recomendados para programas de manejo de pragas na cultura de macieira em associação com esse predador. 
Tabela - 3. Mortalidade acumulada (M) (\%), número médio de ovos/dia/fêmea (R1), viabilidade de ovos (R2) (\%), efeito total (E) (\%) e classe de toxicidade de sete inseticidas para larvas de primeiro ínstar de Chrysoperla externa das populações de Bento Gonçalves e Vacaria, RS. Temp.:25 $\pm 2^{\circ} \mathrm{C}$; UR: $70 \pm 10 \%$; fotofase: $12 \mathrm{~h} ; \mathrm{n}=20$ ).

População de Bento Gonçalves

\begin{tabular}{lccccc} 
Tratamentos & $\mathrm{M}^{1}$ & $\mathrm{R}_{1}{ }^{2}$ & $\mathrm{R}_{2}{ }^{3}$ & $\mathrm{E}^{4}$ & Classe $^{5}$ \\
\hline Fosmet & 80,0 & - & - & 78,95 & 2 \\
$\begin{array}{l}\text { Metoxifenozide } \\
\text { Tebufenozide }\end{array}$ & 15,0 & 12,9 & 84,2 & 32,66 & 2 \\
$\begin{array}{l}\text { Benzoato de } \\
\text { emamectina }\end{array}$ & 20,0 & 14,3 & 91,1 & 33,50 & 2 \\
Spinosad & 25,0 & 14,1 & 92,0 & 10,85 & 1 \\
Etofenprox & 40,0 & 17,4 & 88,4 & 36,42 & 2 \\
Clorpirifós & 100,0 & - & - & 100,76 & 2 \\
Testemunha & 5,0 & 15,9 & 90,7 & - & - \\
\hline
\end{tabular}

População de Vacaria

\begin{tabular}{|c|c|c|c|c|c|}
\hline Tratamentos & $\mathrm{M}^{1}$ & $\mathrm{R}_{1}^{2}$ & $\mathrm{R}_{2}^{3}$ & $\mathrm{E} \%{ }^{4}$ & Classe $^{5}$ \\
\hline Fosmet & 80,0 & - & - & 80,0 & 3 \\
\hline Metoxifenozide & 10,0 & 17,6 & 95,8 & 7,97 & 1 \\
\hline Tebufenozide & 20,0 & 17,8 & 95,0 & 17,91 & 1 \\
\hline $\begin{array}{l}\text { Benzoato de } \\
\text { emamectina }\end{array}$ & 10,0 & 18,6 & 95,4 & 3,50 & 1 \\
\hline Spinosad & 15,0 & 16,4 & 94,3 & 20,27 & 1 \\
\hline Etofenprox & 20,0 & 19,2 & 94,5 & 11,94 & 1 \\
\hline Clorpirifós & 100,0 & - & - & 100,0 & 4 \\
\hline Testemunha & 0 & 17 & 96,9 & - & - \\
\hline
\end{tabular}

${ }^{1}$ Mortalidade (\%) acumulada obtida ao longo do desenvolvimento do predador.

${ }^{2}$ Número médio de ovos/dia/fêmea.

${ }^{3}$ Viabilidade (\%) dos ovos coletados no período de quatro semanas.

${ }^{4}$ Efeito total (\%) dos tratamentos ao longo do desenvolvimento do predador, em que $\mathrm{E}=100 \%-(100 \%-\mathrm{M} \%) \times \mathrm{R}_{1} \times \mathrm{R}_{2}$.

${ }^{5}$ Classe de toxicidade preconizada pela OILB (Hassan et al., 1994), sendo classe 1 = inócuo $(\mathrm{E}<30 \%)$, classe 2 = levemente nocivo $(30 \%=\mathrm{E}=79 \%)$, classe $3=$ moderadamente nocivo $(80 \%=\mathrm{E}=99 \%)$ e classe $4=$ nocivo $(\mathrm{E}>99 \%)$.

\section{REFERÊNCIAS}

ABBOTT, W.S. A method of computing the effectiveness of an insecticide. Journal of Economic Entomology, Lanham, v.18, p.265-267, 1925.

BALASUBRAMANI, V.; SWAMIAPPAN, M. Persistent toxicity of some insecticides to the green lacewing Chrysoperla carnea (Neuroptera: Chrysopidae). Journal of Ecotoxicology and Environmental Monitoring, Dordrecht, v.7, n.3, p.197200, 1997.
BLEICHER, E. Biologia e exigências térmicas de populações de Trichogramma (Hym.: Trichogrammatidae). 1985. 80f. Tese (Doutorado em Entomologia) - ESALQ, Universidade de São Paulo, Piracicaba.

CARLSON, G.R. et al. The chemical and biological properties of methoxyfenozide, a new insecticidal ecdysteroid agonist. Pest Management Science, Hoboken, v.57, n.2, p.115-119, 2001.

CARVALHO, C.F.; SOUZA, B. Métodos de criação e produção de crisopídeos. In: BUENO, V.H.P. (Ed). Controle biológico de pragas: produção massal e controle de qualidade. Lavras: UFLA, 2000. p.91-109.

GODOY, M.S. et al. Seletividade de inseticidas utilizados na cultura dos citros para ovos e larvas de Chrysoperla externa (Hagen) (Neuroptera: Chrysopidae). Neotropical Entomology, Londrina, v.33, n.5, p.639-646, 2004.

HASSAN, S.A. et al. Results of the sixth joint pesticide testing programme of the IOBC/WPRS - Working Group "Pesticides and Beneficial Organisms”. Entomophaga, Paris, v.39, n.1, p.107-119, 1994.

KOVALESKI, A.; RIBEIRO, L.G. Manejo de pragas na produção integrada de maçã. In: PROTAS, J.F.da. S.; SANHUEZA, R.M.V. Produção integrada de frutas: o caso da maçã no Brasil. Bento Gonçalves: EMBRAPA UVA E VINHO, 2003. p.61-68.

LORENZATO, D. Controle biológico de ácaros fitófagos na cultura da macieira no município de Farroupilha, RS. Agronomia Sulriograndense, Porto Alegre, v.23, n.2, p.167183, 1987.

ORTH, A.I. et al. Manejo de pragas. In: EMPRESA DE PESQUISA AGROPECUÁRIA DE SANTA CATARINA (Florianópolis, SC). Manual da cultura da macieira. Florianópolis, 1986. p.341-379.

RETNAKARAN, A. et al. Mode of action of the ecdysone agonist tebufenozide (RH-5992), and an exclusion mechanism to explain resistance to it. Pest Management Science, Hoboken, v.57, n.10, p.951-957, 2001.

RIBEIRO, L.G.; FLORES, E.H. Pulgão-verde: Aphis citricola Van der Goot (Homoptera: Aphididade). In: EPAGRI. A cultura da macieira. Florianópolis: EPAGRI, 2002. Cap.15.4.4, p.519521.

RIBEIRO, M.J. et al. Influência da alimentação larval sobre a biologia de adultos de Chrysoperla externa (Hagen, 1861) (Neuroptera: Chrysopidae). Ciência e Prática, Lavras, v.15, n.2, p.349-354, 1991.

RUMPF, S. et al. Lacewings (Neuroptera: Hemerobiidae and Chrysopidae) and integrated pest management: enzyme activity as biomarker of sublethal insecticide exposure. Journal of Economic Entomology, Lanham, v.90, n.1, p.102-108, 1997.

SAS INSTITUTE. SAS user's guide: statistics. Version 6.12. Cary, NC, 1998. 584p.

VOGT, H. Untersuchungen zu Nebenwirkungen von Insektiziden und Akariziden auf Chrysoperla carnea (Stephens) (Neuroptera: Chrysopidae). Mededelingen van de Faculteeeit van de Universite de Gent, Gent, v.57, n.2, p.559-567, 1992.

WILKINSON, C.F. Insecticide biochemistry and physiology. New York: Plenum, 1976. 768p.

YOSHIMOTO, T. et al. Development of new insecticide, etofenprox. Journal of Pest Science, Tokyo, v.14, n.2, p.259-268, 1989.

Ciência Rural, v.36, n.2, mar-abr, 2006. 